\title{
Conforto térmico para matrizes suínas em fase de gestação, alojadas em baias individuais e coletivas
}

\author{
Héliton Pandorfi', Iran J. O. da Silva ${ }^{2} \&$ Sonia M. S. Piedade ${ }^{2}$
}

\begin{abstract}
RESUMO
Este experimento foi realizado no período compreendido entre 04/01 e 11/03/2005, em uma propriedade de produção industrial de suínos, localizada no município de Elias Fausto, estado de São Paulo. O objetivo da pesquisa consistiu na avaliação de diferentes sistemas de alojamento para matrizes gestantes, verificando-se as influências dos elementos meteorológicos e os aspectos relacionados à qualidade química do ar e seus reflexos no conforto animal na fase de gestação, determinando-se as condições favoráveis ao melhor desempenho animal, com base nas respostas ao ambiente de criação. O estudo foi desenvolvido no setor de gestação, com 24 matrizes primíparas, 12 fêmeas alojadas em baias individuais (T1) e 12 animais em baias coletivas (T2). O trabalho foi dividido em duas etapas: análise bioclimática e análise da qualidade química do ar. O delineamento experimental foi em blocos casualizados, com dois tratamentos e 67 blocos, e as médias comparadas pelo teste de Tukey. As variáveis meteorológicas $\left(\mathrm{T},{ }^{\circ} \mathrm{C} \mathrm{e} \mathrm{h,} \mathrm{k} \mathrm{kg}^{-1}\right.$ ) apontam o sistema de alojamento em baias coletivas como aquele que permitiu melhor condicionamento térmico natural às matrizes em gestação apresentando valores da ordem de $25,03{ }^{\circ} \mathrm{C}$ e $62,02 \mathrm{~kJ} \mathrm{~kg}^{-1}$. As concentrações dos teores de gases não superaram as concentrações consideradas críticas para as matrizes.
\end{abstract}

Palavras-chave: biometeorologia animal, sistema de produção, suinocultura

\section{Thermal comfort for pregnant sows housed in individual and group stalls}

\begin{abstract}
The experiment was carried out from January 4 to March 11, 2005 in a farm specialized in industrial production of pork, located in Elias Fausto, São Paulo State. This study evaluated different housing systems for pregnant sows looking at meteorological element influences and aspects of air chemical quality on the animal thermal comfort. The optimal conditions for animal performance improvement were determined by analyzing behavioral data taken in the breeding environment. In the gestation facility 24 gilts were allocated: 12 in individual stalls (T1) and 12 in group housings (T2). This study was divided into two steps: bioclimatic analysis and analysis of the chemical quality of air. An experimental design using randomized blocks with two treatments and 67 blocks was used. Means were compared by the Tukey test. The variables $\left(\mathrm{T},{ }^{\circ} \mathrm{C}\right.$ e h, $\mathrm{kJ} \mathrm{kg}^{-1}$ ) indicated which confinement system in group-houses was the one that permitted the better natural thermal environment for pregnant gilts with values of $25.03{ }^{\circ} \mathrm{C}$ and $62.02 \mathrm{~kJ} \mathrm{~kg}^{-1}$. In relation to concentration of gases, mean levels did not exceed the concentrations considered limiting for sows.
\end{abstract}

Key words: animal biometeorology, production system, swine production

${ }^{1}$ NUPEA - Departamento de Tecnologia Rural/UFRPE. Rua Dom Manuel de Medeiros s/n, CEP 52171-900, Recife, PE. Fone: (81) 3220-6261. E-mail: pandorfi@dtr.ufrpe.br

2 NUPEA - ESALQ/USP. Av. Pádua Dias 11, CEP 13418-900, Piracicaba, SP. Fone: (19) 3429-4217 - r. 238. E-mail: ijosilva@esalq.usp.br 


\section{INTRODUÇÃO}

O ambiente do sistema de criação intensivo na suinocultura exerce influência direta na condição de conforto e bemestar animal, promovendo dificuldade na manutenção do balanço térmico no interior das instalações e na qualidade química do ar, afetando o desempenho produtivo e reprodutivo dos suínos.

O suíno é considerado um agente modificador do meio em que vive, seja através da geração de calor, vapor d'água, fezes, urina ou como foco de desenvolvimento de patógenos. Nessas condições, o verdadeiro ambiente passa a ser aquele reinante no interior da edificação ou aquele cujo ar os animais respiram (Benedi, 1986).

A temperatura ambiente considerada ótima para a matriz varia entre 7 e $23{ }^{\circ} \mathrm{C}$ (Noblet et al., 1989; Lucas \& Cruz, 1997) sendo que altas temperaturas no interior das instalações influenciam negativamente a eficiência reprodutiva. Em locais onde as temperaturas no verão foram superiores a $24^{\circ} \mathrm{C}$, verificou-se diminuição da fertilidade das fêmeas suínas e alta porcentagem de retorno ao cio (Bortolozzo et al., 1997; Wentz et al., 1997; Peltoniemi et al., 1999), principalmente nas fêmeas primíparas (Vieira \& Vieira, 1987), atraso da maturidade sexual (Flores et al., 1989; Perez y Perez \& Guitierrez, 1987) e maior mobilização de gordura corporal durante a lactação (Barb et al., 1991).

O suíno apresenta dificuldade para dissipar calor em ambiente de alta temperatura e umidade, pois o excesso de umidade restringe as perdas evaporativas pela respiração e contribui para diminuir o apetite. A elevação da umidade relativa de 45 para $90 \%$ a uma temperatura de $21{ }^{\circ} \mathrm{C}$, é responsável pela redução em até $8 \%$ das perdas de calor, sendo que o ideal para suínos em condições satisfatórias de temperatura é de uma umidade relativa entre 60 e $70 \%$ (Nienaber et al., 1987).

Nos sistemas de criação de suínos os limites para as concentrações de gases tóxicos variam por não existir uma norma no estrito senso do termo (Gustafsson et al., 1999; Perdomo et al., 2001; Chang et al., 2001; Sampaio et al., 2005; Sampaio et al., 2006).

Segundo a Commission Internationale du Génie Rural (CIGR, 1994), os gases são provenientes da respiração dos animais e de outras fontes, como a decomposição microbiana de urina e fezes, afetada pela temperatura, $\mathrm{pH}$ e umidade da massa de excrementos.

Altas concentrações de $\mathrm{NH}_{3}$, acima de 30 ppm podem ser responsáveis pelo desenvolvimento de inflamações nas vias respiratórias de suínos culminando em redução do ganho de peso. $\mathrm{O} \mathrm{H}_{2} \mathrm{~S}$ entre 50-200 ppm pode acarretar sintomas como perda de apetite, fotofobia, vômito e diarréia. Valores superiores a $20.000 \mathrm{ppm}$ de $\mathrm{CO}_{2}$ provocam aumento dos batimentos cardíacos, sonolência e dor de cabeça (Perdomo et al., 2001).

As normas da União Européia (UE) referentes às matrizes gestantes preconizam alojamento coletivo em estabulação livre, para permitir um contato social adequado, proibindo instalações em que os animais sejam mantidos isolados com utilização de celas, coleiras ou cintas, fase em que o alojamento individual é permitido antes da cobrição, inseminação ou para tratamento, definindo-se um período de adaptação aos sistemas de contenção existentes até $1^{\circ}$ de janeiro de 2006.

Com base neste fato é conveniente lembrar que qualquer proposta relativa ao bem-estar dos suínos deve basear-se em resultados de estudos científicos realizados com animais de produção, evitando possíveis distorções do mercado comum europeu frente a importações de carne suína de países exportadores.

Assim, o objetivo desta pesquisa consistiu na avaliação de diferentes sistemas de alojamento para matrizes gestantes, verificando-se as influências dos elementos meteorológicos e os aspectos relacionados à qualidade química do ar e seus reflexos no conforto animal na fase de gestação, em uma produção industrial de suínos.

\section{MATERIAL E MÉTODOS}

O experimento foi realizado em uma granja comercial cuja principal atividade é a produção industrial de suínos, localizada no município de Elias Fausto, SP, hoje um laboratório experimental do NAP - NUPEA/USP, latitude de $22^{\circ} 36^{\prime} \mathrm{S}$, longitude de $47^{\circ} 36^{\prime} \mathrm{W}$ e altitude de $535 \mathrm{~m}$. O clima da região é caracterizado como mesotérmico Cwa (tropical de altitude), com temperatura do mês mais frio entre 3 e $18{ }^{\circ} \mathrm{C}$, com inverno seco e temperatura do mês mais quente maior que $22^{\circ} \mathrm{C}$, segundo classificação de Köppen (Pereira et al., 2002).

Foram avaliados dois sistemas de confinamento considerados neste trabalho, nos tratamentos: confinamento em baias individuais de gestação (T1) e coletivas (T2).

A instalação referente ao confinamento das matrizes gestantes é caracterizada, tipologicamente, por $60 \mathrm{~m}$ de comprimento por $15 \mathrm{~m}$ de largura, pé direito de $2,3 \mathrm{~m}$, beiral de $0,5 \mathrm{~m}$ com orientação leste-oeste. A cobertura é de telhas de cerâmica do tipo francesa sem forro de revestimento, apresentando fechamento lateral em alvenaria no sentido longitudinal da instalação, com peitoril de $1,10 \mathrm{~m}$, totalizando uma área de abertura lateral de $144 \mathrm{~m}^{2}$.

As baias individuais de contenção possuem dimensões de $1,95 \mathrm{~m}$ de comprimento por $0,60 \mathrm{~m}$ de largura e $1,20 \mathrm{~m}$ de altura, totalizando uma área de $1,17 \mathrm{~m}^{2}$ e volume de $1,40 \mathrm{~m}^{3}$. $\mathrm{O}$ piso das baias é concretado, apresentando no terço final piso vazado confeccionado em concreto armado.

As baias coletivas apresentam as seguintes dimensões: 4,80 m de comprimento por 2,80 $\mathrm{m}$ de largura e muretas de contenção de $1,10 \mathrm{~m}$ de altura, com ripado de bambu no terço final, de maneira a garantir sombreamento aos animais, como medida de proteção a possíveis doenças de pele, eritema solar, resultantes da exposição direta à radiação solar; além disso, possui piso concretado sem substrato ou cama disponível, totalizando uma área livre de $13,44 \mathrm{~m}^{2}$, dispondo de 2,24 $\mathrm{m}^{2}$ por animal. Os grupos foram formados por seis animais no total.

O controle do microclima no interior da edificação foi realizado com o acionamento dos sistemas de aspersão no 
telhado e de nebulização nas linhas das baias individuais. Os sistemas de climatização eram acionados em dias em que a temperatura excedia os $30^{\circ} \mathrm{C}$, normalmente às $12 \mathrm{~h}$, permanecendo em funcionamento até as $17 \mathrm{~h}$; além disso, contava-se com as aberturas no telhado, pela retirada de telhas, o que permitia maior dissipação do calor transmitido pela radiação e gerado pelos animais.

Foram alojadas, na estrutura, 380 matrizes, $270 \mathrm{em}$ baias individuais e 110 animais em baias coletivas. A disposição dos sistemas de alojamento no sentido transversal da edificação caracteriza-se de forma que as baias coletivas ocupem uma das extremidades laterais e as baias individuais, o restante de toda a construção.

$\mathrm{O}$ estudo foi realizado com animais da raça característica da granja (Landrace e Large White) e fêmeas de genética da própria granja, resultante do cruzamento das matrizes avós e machos híbridos comerciais (PIC-412 Agroceres). As matrizes selecionadas eram de mesma ordem de parto, com o objetivo de eliminar fatores de interferência, habilidade materna, número de leitões por leitegada. Foram selecionadas 12 marrãs para observação no sistema de confinamento em baias individuais de gestação (T1) e 12 animais em baias coletivas (T2), divididas em dois grupos de seis animais, totalizando 24 primíparas para comparação dos sistemas de criação.

As fêmeas foram cobertas a partir dos seis meses de idade $( \pm 130 \mathrm{~kg})$, alojadas em grupo até a detecção de cio, quando foram recolhidas e inseminadas em baias individuais, nelas permanecendo durante o período de 45 dias e, posteriormente, distribuídas de forma aleatória, nos respectivos tratamentos.

A alimentação foi feita com ração à base de milho e sorgo, capaz de fornecer $3.250 \mathrm{kcal} \mathrm{EM} \mathrm{dia}^{-1}$, formulada segundo recomendações do NRC (1998) e distribuída na base de $2,0 \mathrm{~kg} \mathrm{dia}^{-1}$ do $1^{\circ}$ ao $30^{\circ}$ dia; $2,2 \mathrm{~kg} \mathrm{dia}^{-1}$ do $31^{\circ}$ ao $85^{\circ}$ dia; $3,0 \mathrm{~kg} \mathrm{dia}^{-1}$ do $86^{\circ}$ ao $110^{\circ}$ e $2,0 \mathrm{~kg} \mathrm{dia}^{-1}$ do $111^{\circ}$ ao $114^{\circ}$ dia de gestação, fornecida uma única vez ao dia, às $7 \mathrm{~h}$.

$\mathrm{O}$ desenvolvimento da pesquisa foi realizado no período compreendido entre 04/01 a 11/03/2005, com duração média de 67 dias. $\mathrm{O}$ experimento foi dividido em duas etapas: análise bioclimática e avaliação da qualidade química do ar.

Foram monitoradas variáveis meteorológicas e ambientais (concentração de gases) na sala de gestação e no ambiente externo. As variáveis meteorológicas foram registradas por meio de sensores instalados no interior da instalação a uma altura de 1,30 $\mathrm{m}$ do piso, dispostos pontualmente na condição de alojamento em baias coletivas e individuais determinando, desta forma, o microclima proporcionado por cada um dos sistemas de alojamento estudados. No ambiente externo foram conectados a uma plataforma automática de registro, os seguintes dados: temperatura de bulbo seco (Ts), umidade relativa do ar (UR), temperatura de ponto de orvalho (Tpo), temperatura de globo negro (Tg) e umidade absoluta (UA).

$\mathrm{Na}$ área externa às instalações os sensores foram instalados a 1,5 m de altura da superfície, representando o microclima do local. A aquisição dos dados foi realizada por meio de um datalogger da marca Hobo, modelo H08-00X-08, ope- rando na faixa de $-30{ }^{\circ} \mathrm{C} \mathrm{a}+50{ }^{\circ} \mathrm{C}$, e sensor de umidade à prova de condensação com registro de dados entre 0 e 100 $\%$.

O registro das variáveis meteorológicas foi realizado em intervalos de 15 min, durante o ciclo de gestação das matrizes selecionadas para o estudo. As variáveis meteorológicas foram registradas por um datalogger da marca Hobo, modelo H08-00X-02, equipado com sensor de temperatura externa (globo negro); sua faixa de operação encontra-se entre -20 e $+70^{\circ} \mathrm{C}$ e umidade relativa de 0 a $95 \%$, sem condensação ou névoa.

Para determinação da eficiência térmica das instalações com os dados referentes às variáveis meteorológicas registradas nos ambientes estudados, foram determinados o índice de temperatura de globo e umidade (ITGU) e entalpia específica $h$ ( $\mathrm{kJ} \mathrm{kg}^{-1}$ ar seco) por meio das seguintes equações:

a) índice de temperatura de globo e umidade (ITGU), proposta por Buffington et al. (1981):

$$
\mathrm{ITGU}=\mathrm{Tg}+0,36 \mathrm{TPo}-330,08
$$

em que: Tg - temperatura de globo negro $(\mathrm{K})$ e Tpo - temperatura de ponto de orvalho (K).

b) entalpia ( $\mathrm{kJ} \mathrm{kg}$ ar $\mathrm{seco}^{-1}$ ), proposta por Albright (1990):

$$
\mathrm{H}=1,006 \mathrm{Ts}+\mathrm{W}(2501+1,805 \mathrm{Ts})
$$

em que: Ts - temperatura de bulbo seco $\left({ }^{\circ} \mathrm{C}\right)$ e $\mathrm{W}$ - razão de mistura ( $\mathrm{kg}$ vapor d'água $\mathrm{kg}$ ar $\left.\mathrm{seco}^{-1}\right)$.

As recomendações da CIGR (1994) e por Sampaio (2004) para concentração de amônia $\left(\mathrm{NH}_{3}\right)$, sulfeto de hidrogênio $\left(\mathrm{H}_{2} \mathrm{~S}\right)$, monóxido de carbono $(\mathrm{CO})$ e dióxido de carbono $\left(\mathrm{CO}_{2}\right)$ aos animais, são apresentadas na Tabela 1.

Tabela 1. Recomendação máxima de amônia $\left(\mathrm{NH}_{3}\right)$, sulfeto de hidrogênio $\left(\mathrm{H}_{2} \mathrm{~S}\right)$, monóxido de carbono $(\mathrm{CO})$ e dióxido de carbono $\left(\mathrm{CO}_{2}\right)$ em instalações para suínos

\begin{tabular}{ccc}
\hline Gases & Concentração máxima $(\mathbf{p p m})$ & Observação \\
$\mathrm{NH}_{3}$ & 20 & Zona dos animais \\
$\mathrm{H}_{2} \mathrm{~S}$ & 0,5 & Zona dos animais \\
$\mathrm{CO}$ & 10 & Ambiente \\
$\mathrm{CO}_{2}$ & 3000 & - \\
\hline
\end{tabular}

Fonte: CIGR (1994); Sampaio (2004)

O registro da concentração de gases foi realizado semanalmente, por amostragem completa da jornada, durante $8 \mathrm{~h} \mathrm{(7}$ às $17 \mathrm{~h}$ ). No período de avaliação dos locais estudados verificaram-se as concentrações dos gases existentes no ar por meio de sensores eletroquímicos de $\mathrm{O}_{2}, \mathrm{CH}_{4}, \mathrm{NH}_{3}, \mathrm{CO}$ e $\mathrm{H}_{2} \mathrm{~S}$, instalados no centro geométrico da construção, a uma altura de 1,2 $\mathrm{m}$ do piso, utilizando-se o equipamento Commander ${ }^{\circledR}$ para o monitoramento dos gases no interior da instalação.

O delineamento experimental adotado foi em blocos casualizados (DBC) tendo-se como tratamentos, os sistemas de confinamento em baias de gestação individuais e coletivas. As variáveis meteorológicas e ambientais foram analisadas adotando-se o DBC para análise geral e o teste de Tukey 
$(\mathrm{P}<0,01)$ para a comparação entre as médias. Realizaramse análises horárias durante o período do estudo (67 dias consecutivos), adotando-se o programa estatístico Statistical Analysis System (SAS, 1992).

\section{RESULTADOS E DISCUSSÃO}

A comparação entre tratamentos e o ambiente externo apresentados na Tabela 2, é resultado médio diário das variáveis respostas da subdivisão do microambiente estudado (sala de gestação) e seus respectivos sistemas de contenção, baias individuais (T1) e baias coletivas (T2). Os tratamentos apresentaram diferenças significativas para temperatura de bulbo seco (Ts) quando comparados entre si, com maior temperatura no T1, em virtude do maior número de animais alojados (animal $\mathrm{m}^{-2}$ ) neste sistema de contenção. Pelo aporte de energia gerado pelos animais, o T2 apresentou menor Ts comparativamente ao T1, fato este atribuído à própria disposição das baias coletivas que ficavam sujeitas a maior renovação de ar.

Tabela 2. Valores médios* diários das variáveis ambientais para 0 sistema de confinamento em baias individuais (T1), coletivas (T2) e no ambiente externo

\begin{tabular}{cccccc}
\hline & Ts ( $\left.{ }^{\circ} \mathbf{C}\right)$ & UR (\%) & Tg $\left(^{\circ} \mathbf{C}\right)$ & ITGU & h (kJ kg-1 $)$ \\
T1 & $25,47 \mathrm{a}$ & $70,48 \mathrm{~b}$ & $25,20 \mathrm{a}$ & $73,40 \mathrm{a}$ & $63,47 \mathrm{a}$ \\
T2 & $25,03 \mathrm{~b}$ & $70,14 \mathrm{~b}$ & $25,20 \mathrm{a}$ & $73,56 \mathrm{a}$ & $62,02 \mathrm{~b}$ \\
Externo & $24,48 \mathrm{c}$ & $79,65 \mathrm{a}$ & $24,47 \mathrm{a}$ & $73,46 \mathrm{a}$ & $63,51 \mathrm{a}$ \\
\hline
\end{tabular}

* Valores médios com letras diferentes, na mesma coluna, diferem estatisticamente pelo Teste de Tukey, $\mathrm{P}<0,01$

Com relação à umidade relativa do ar (UR) e à temperatura de globo negro (Tg), nenhuma dessas variáveis apresentou diferenças estatísticas entre tratamentos; porém no ambiente externo a UR média foi maior, caracterizando a condição de entorno à instalação, superfície com cobertura vegetal e arborização.

Para o índice de temperatura de globo e umidade (ITGU) os valores médios diários não mostraram diferenças significativas, a exemplo das variáveis que integram o modelo Tg e temperatura de ponto de orvalho (Tpo). Os dados médios para a entalpia (h) apontaram diferenças significativas entre tratamentos, verificando-se maior quantidade de energia na parcela de ar referente ao sistema de contenção em baias individuais, com valor próximo àquele registrado no ambiente externo.

A Figura 1 evidencia o efeito da temperatura nos diferentes tratamentos, baias coletivas e individuais e no ambiente externo, condições em que o condicionamento térmico no interior da instalação esteve acima da condição recomendada, na qual a temperatura ambiente considerada ótima para a matriz varia entre 18 e $23{ }^{\circ} \mathrm{C}$ (Yan \& Yamamoto, 2000; Brown-Brandl et al., 2001), ficando evidente que a condição de conforto proporcionada aos animais está inadequada. Verifica-se que, no decorrer do período avaliado a temperatura média diária permaneceu, durante a maior parte do tempo, superior aos $23{ }^{\circ} \mathrm{C}$, caracterizando-se como situação de alerta a possíveis problemas reprodutivos, principalmente em fêmeas primíparas (Bortolozzo et al., 1997; Wentz et al., 1997; Peltoniemi et al., 1999).

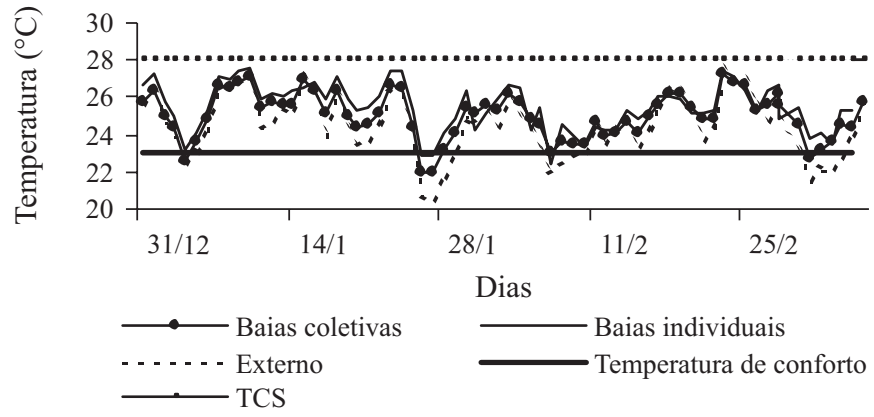

Figura 1. Variação da temperatura média diária nos diferentes tratamentos na sala de gestação e no ambiente externo

Reforçando a afirmação acima, pode-se observar, na Figura 1, que durante o estudo as temperaturas médias se mantiveram próximas à faixa de conforto dos animais, entre 23 e $24{ }^{\circ} \mathrm{C}$, em apenas $18 \%$ do tempo total de registro para ambos os tratamentos mas a temperatura se encontrou, durante toda a fase avaliada, abaixo da temperatura crítica superior (TCS) não atingindo, na média, valores da ordem de $28{ }^{\circ} \mathrm{C}$ (Mount \& Seabrook, 1993; Silva, 1999) promovendo condições inadequadas em que os animais submetidos a esses ambientes passariam a sofrer estresse calórico e reflexo direto na manutenção dos processos reprodutivos.

$\mathrm{Na}$ tentativa de se evidenciar o efeito do condicionamento térmico das matrizes, selecionaram-se os dias críticos do período estudado, que apresentaram maior (25/02) e menor (28/01) valor para entalpia (Moura et al., 1997); desta forma se verifica, na Figura 2A, que entre as 11 e $19 \mathrm{~h}$, a temperatura no interior da sala de gestação esteve acima da TCS para o T2, embora tenha atingindo um pico de temperatura às $16 \mathrm{~h}$, em que se registrou um valor da ordem de $32,86{ }^{\circ} \mathrm{C}$.

A intensidade e a duração dos períodos de elevação de temperatura estão associadas à dificuldade de fertilização e podem afetar a fixação e a sobrevivência dos conceptos, principalmente na fase inicial de gestação podendo, também, causar

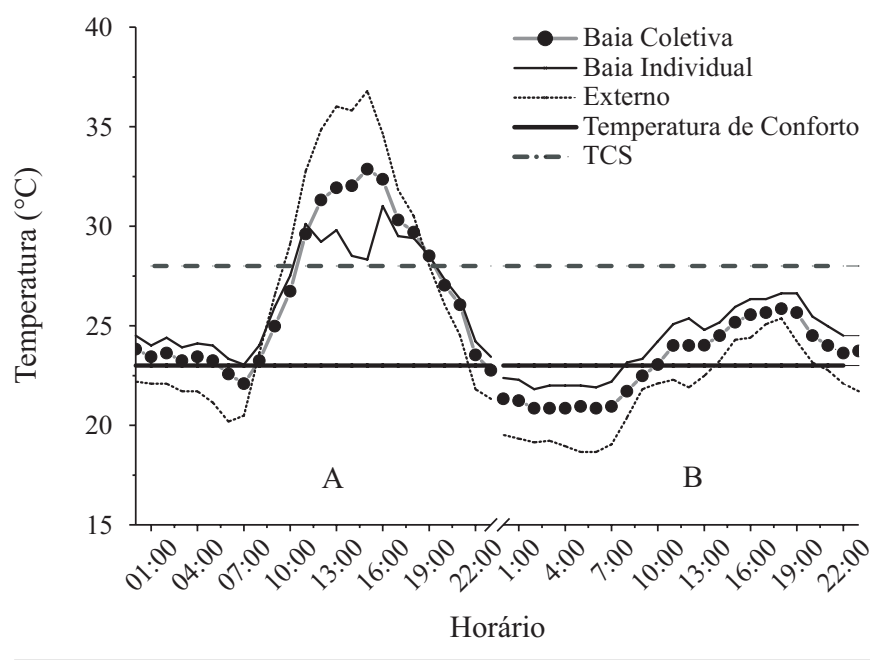

Figura 2. Variação da temperatura média horária para o dia crítico de maior (A) e menor (B) entalpia, nos diferentes tratamentos, na sala de gestação e no ambiente externo 
diminuição do fluxo sangüíneo uterino, hipertermia maternal, alteração no metabolismo endócrino das fêmeas, maior taxa de retorno ao cio, menor taxa de parição e tamanho de leitegada (Brandt et al., 1995; Bortolozzo et al., 1997).

No que se refere às baias individuais (T1) observa-se que, entre os horários das 11 às $19 \mathrm{~h}$, a temperatura apresentou pequenas oscilações frente à linha da TCS, mostrando-se sempre inferior àquela registrada nas baias coletivas; esta variação é o resultado da modificação do ambiente em virtude do uso de um recurso de resfriamento, já que a instalação dispunha de uma linha de nebulização para os animais alojados nas baias individuais, que era acionada manualmente por um funcionário da granja, sempre que a temperatura excedia os $30^{\circ} \mathrm{C}$, reduzindo o efeito do ambiente térmico sobre as matrizes.

Neste contexto verifica-se, na Figura 2A, que a temperatura máxima registrada no $\mathrm{T} 2$ foi de $32,86^{\circ} \mathrm{C}$ e a mínima de $22,09{ }^{\circ} \mathrm{C}$, resultando em uma amplitude de $10,70{ }^{\circ} \mathrm{C}$; de maneira análoga se tem, para o $\mathrm{T} 1$, temperatura máxima de $31,02{ }^{\circ} \mathrm{C}$ e mínima de $23,05^{\circ} \mathrm{C}$, gerando uma amplitude de $7,17^{\circ} \mathrm{C}$, destacando-se o $\mathrm{T} 1$ como aquele que melhor se adequa às necessidades dos animais, frente à eficiência do sistema de climatização adotado.

Para a segunda condição tem-se, na Figura 2B, que a variação da temperatura no decorrer do dia selecionado (28/ 01) apresentou valores inferiores para o T2, comparativamente a T1, evidenciando um condicionamento melhor para as baias coletivas que se mostraram, em média, mais próximas da condição de conforto das matrizes. Vê-se que os dois tratamentos mativeram-se dentro da faixa recomendada, isto é, entre os valores de 23 e $28^{\circ} \mathrm{C}$. A amplitude térmica registrada para o dia de menor entalpia foi de $4,99{ }^{\circ} \mathrm{C}$ para as baias coletivas e de $4,82^{\circ} \mathrm{C}$ para as individuais, evidenciando sua redução, comparativamente ao dia de maior entalpia, ensejando condição mais propícia aos animais.

O desempenho da edificação estudada revela um quadro de desconforto térmico com temperaturas excessivas, decorrentes principalmente da deficiência da ventilação e da densidade dos animais. Esses aspectos constituem os principais entraves para se alcançar as metas para a otimização econômica do setor, no que tange aos índices zootécnicos. Os problemas gerados não decorrem apenas da concepção arquitetônica da construção mas, também, da ausência da hierarquização das exigências do animal e da determinação dos limites extremos da aceitabilidade ambiental.

Com base nas variáveis meteorológicas discutidas até o momento, verifica-se que o desempenho e o layout de distribuição dos animais no sistema de confinamento em baias coletivas, permitiram melhor condicionamento térmico natural às matrizes em gestação, considerando-se sua localização no interior da edificação que potencializava as trocas convectivas de calor por meio da ventilação natural e pelo fato de se dispor de maior área por animal, porém o conceito de qualidade do ambiente de produção é amplo e, por sua vez, envolve aspectos relacionados ao microclima, à qualidade do ar, às respostas fisiológicas e produtivas dos animais e aos seus reflexos comportamentais.

Isto posto, nota-se que as novas regulamentações da UE dirigidas ao bem-estar animal podem envolver aspectos relacionados a alterações no sistema de alojamento de matrizes gestantes, proibindo a utilização de baias individuais para porcas ou marrãs, de maneira a permitir um aumento na área livre destinada aos animais desta categoria, visando garantir conforto térmico aos animais.

As concentrações médias horárias de sulfeto de hidrogênio $\left(\mathrm{H}_{2} \mathrm{~S}\right)$, metano $\left(\mathrm{CH}_{4}\right)$, monóxido de carbono $(\mathrm{CO})$, oxigênio $\left(\mathrm{O}_{2}\right)$ e amônia $\left(\mathrm{NH}_{3}\right)$ na sala de gestação, são apresentadas na Tabela 3 .

Tabela 3. Concentração média horária dos gases $\mathrm{H}_{2} \mathrm{~S}, \mathrm{CO}, \mathrm{CH}_{4} \mathrm{O}_{2} \mathrm{e}$ $\mathrm{NH}_{3}$ no interior da sala de gestação

\begin{tabular}{lccccccccccc}
\hline \multirow{2}{*}{ Gases } & \multicolumn{10}{c}{ Horários $(\boldsymbol{h})$} \\
\cline { 2 - 13 } & $\mathbf{7}$ & $\mathbf{8}$ & $\mathbf{9}$ & $\mathbf{1 0}$ & $\mathbf{1 1}$ & $\mathbf{1 2}$ & $\mathbf{1 3}$ & $\mathbf{1 4}$ & $\mathbf{1 5}$ & $\mathbf{1 6}$ & $\mathbf{1 7}$ \\
$\mathrm{H}_{2} \mathrm{~S}(\mathrm{ppm})$ & 0 & 0 & 0 & 0 & 0 & 0 & 0 & 0 & 0 & 0 & 0 \\
$\mathrm{CO}(\mathrm{ppm})$ & 0 & 0 & 0 & 0 & 0 & 0 & 0 & 0 & 0 & 0 & 0 \\
$\mathrm{CH}_{4}(\%)$ & 0 & 0 & 0 & 0 & 0 & 0 & 0 & 0 & 0 & 0 & 0 \\
$\mathrm{O}_{2}(\%)$ & 20,9 & 20,9 & 20,9 & 20,9 & 20,9 & 20,9 & 20,9 & 20,9 & 20,9 & 20,9 & 20,9 \\
$\mathrm{NH}_{3}(\mathrm{ppm})$ & 2,1 & 1,9 & 1,0 & 0,7 & 1,5 & 1,4 & 2,5 & 3,9 & 5,1 & 6,6 & 7,2 \\
\hline
\end{tabular}

Foram encontrados apenas traços de sulfeto de hidrogênio (H2S), monóxido de carbono (CO) e metano (CH4), correspondendo ao limite de resolução do equipamento.

Os valores de oxigênio $\left(\mathrm{O}_{2}\right)$ mantiveram-se dentro das condições recomendadas, verificando-se valores estáveis, da ordem de 20,9\%. A presença de oxigênio em nível adequado pode ser considerada indicativo de que não há risco no ambiente quanto à presença dos gases asfixiantes $\left(\mathrm{CH}_{4} \mathrm{e}\right.$ $\mathrm{CO}_{2}$ ), os quais deslocam o oxigênio, conforme descrito por Saliba \& Corrêa (2000).

Pode-se verificar que os valores obtidos para concentração de amônia $\left(\mathrm{NH}_{3}\right)$ no interior da instalação foram inferiores para as concentrações admitidas de 10 ppm (Benedi, 1986), mesmo considerando o horário de pico às $17 \mathrm{~h}$, apresentando valor médio da ordem de 7,2 ppm (Larry et al., 1994). Atribui-se a baixa concentração de amônia na sala de gestação ao manejo adotado pela granja, que consistia na raspagem diária de dejetos nas baias individuais (período da manhã) e a lavagem das baias coletivas (período da tarde).

Nota-se, na Figura 3 que, em geral, os teores de amônia $\left(\mathrm{NH}_{3}\right)$ apresentaram variação crescente com o aumento da temperatura no interior da instalação, concordando com Aarnink \& Elzing (1998) e Sampaio (2006).

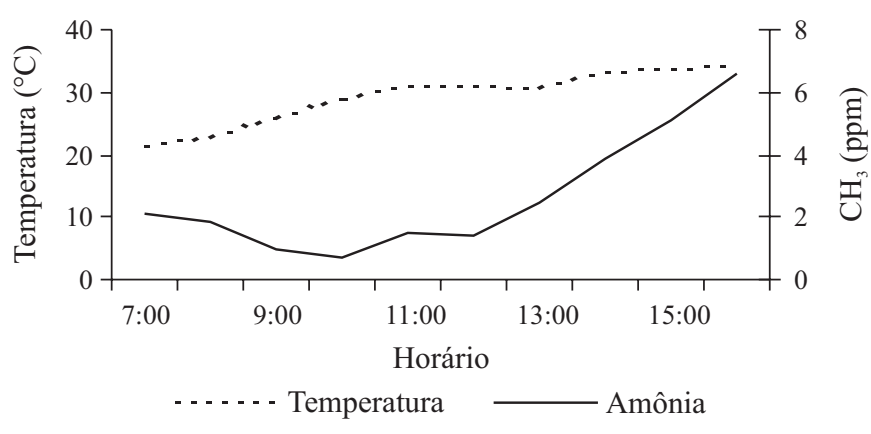

Figura 3. Variação da concentração de amônia e da temperatura no interior da sala de gestação 
Para os dados referentes à concentração de amônia em função da variação da temperatura, utilizou-se análise de regressão polinomial, envolvendo dados médios horários de registro, procurando-se melhor ajuste do modelo. Nota-se, na Figura 4, boa correlação entre as variáveis, apresentando um coeficiente de determinação de 0,86 , significativo a $1 \%$ de probabilidade pelo teste F. De acordo com o modelo desenvolvido para esta situação, a emissão deste gás apresenta um acréscimo de 2,45 até limites de $18,51 \%$ para cada aumento de $1{ }^{\circ} \mathrm{C}$ de temperatura.

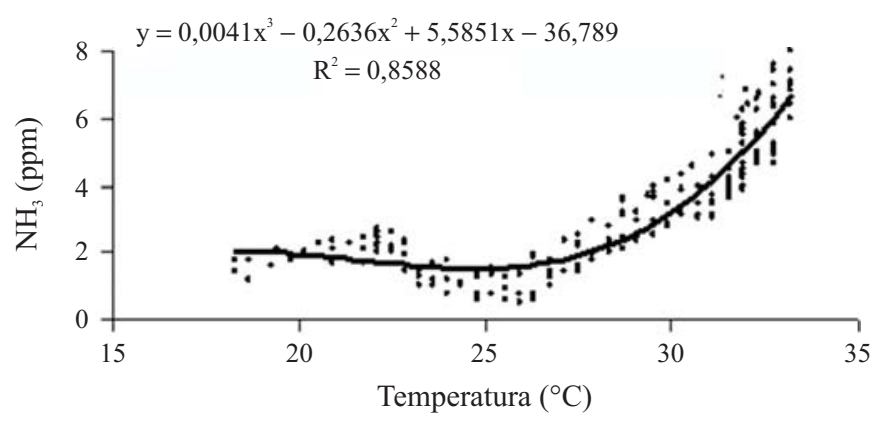

Figura 4. Relação funcional entre concentração de amônia $\left(\mathrm{NH}_{3}\right)$ e a variação da temperatura no interior da instalação

As pequenas flutuações observadas entre os horários das 8 às $12 \mathrm{~h}$, em que não se verificou aumento na concentração de amônia com o aumento da temperatura são devidas à retirada dos dejetos logo após o arraçoamento, entre as 8 e 9 h; posterior à limpeza e com o acúmulo de excretas no decorrer do dia, a concentração de amônia varia mais acentuadamente com o aumento da temperatura (Figura 5); observase, neste período, maior inatividade animal, ou seja, maior tempo de permanência na posição deitada ventral e lateral, haja vista que o piso nas baias individuais é semi-ripado o que permitia escoamento dos dejetos para o fosso e os animais, ao se deitarem, impediam a mistura da amônia volatilizada com o ar, verificando-se menor teor de amônia no ar, neste intervalo de tempo; entretanto, no decorrer do dia, com o acúmulo de dejetos na sala de gestação, a influência da temperatura na concentração de $\mathrm{NH}_{3}$ fica mais evidente, independente da postura dos animais.

Com relação à qualidade química do ar, os teores médios para os gases registrados no interior da instalação não supe-

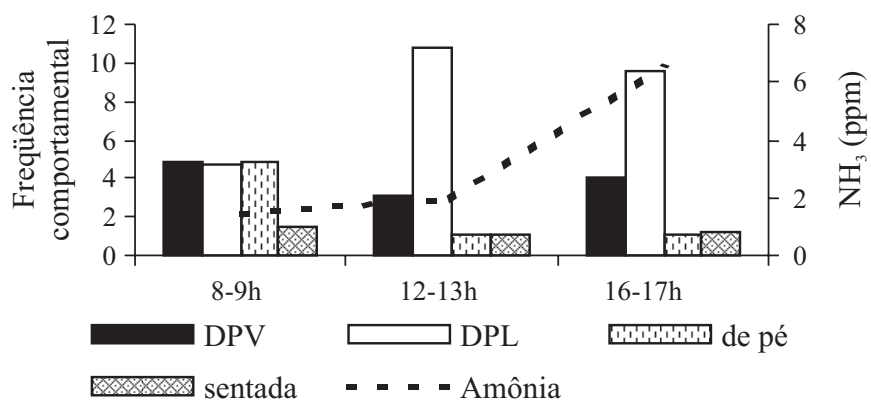

Figura 5. Variação da concentração de amônia em relação à postura dos animais no interior da sala de gestação. Deitada na posição ventral (DPV), deitada na posição lateral (DPL) raram, na maior parte do tempo, os valores considerados críticos para matrizes em fase de gestação. A concentração média de amônia $\left(\mathrm{NH}_{3}\right)$ registrada no centro geométrico da instalação a 1,20 $\mathrm{m}$ do piso, excedeu em alguns horários na parte da tarde, chegando a picos de 8 ppm, superando a concentração recomendada como segura, ou seja, de 7 ppm (Donham, 1999), mas este valor encontrado deve tratar-se de um caso típico de problemas relacionados à baixa taxa de renovação de ar, reduzindo a ventilação sanitária pois a instalação se encontrava em uma cota inferior ao setor de creche que funcionava como obstáculo à renovação de ar da estrutura, prejudicando principalmente os animais alojados nas baias individuais.

\section{CONCLUSÕES}

1. Dentre os sistemas de alojamento para matrizes gestantes, aquele que se mostrou mais adequado às condições de conforto e bem-estar animal foi o confinamento em baias coletivas.

2. Com relação à qualidade química do ar, os teores médios para os gases registrados no interior da instalação não superaram, na maior parte do tempo, os valores considerados críticos para matrizes em fase de gestação.

\section{LITERATURA CITADA}

Aarnink, A. J. A.; Elzing, A. Dynamic model for ammonia volatilization in housing with partially slatted floors, for fattening pigs. Livestock Production Science, v.53, p.153169, 1998.

Albright, L. D. Environment control for animals and plants. St. Joseph: American Society of Agricultural Engineers Michigan. 1990. 453p. ASAE Textbook, 4.

Barb, C. R.; Estienne, M. J.; Kraeling, R. R.; Marple, D. N.; Rampacek, G. B.; Rahe, C. H.; Sartin, J. L. Endocrine changes in sows exposed to elevated ambient temperature during lactation. Domestic Animal Endocrinology, v.8, p.117-1127, 1991.

Benedi, J. M. H. El ambiente de los alojamientos ganaderos. Hojas divulgadoras, v.6, n.1, p.1-28, 1986.

Bortolozzo, F. P.; Wentz, I.; Brandt, G.; Nobre Jr., A. Influência da temperatura corporal sobre a eficiência reprodutiva em fêmeas suínas. In: Congresso Brasileiro de Veterinários Especialistas em Suínos, 1997. Foz do Iguaçu. Anais... Foz do Iguaçu: Abraves, 1997. p.281-282.

Brandt, G.; Wentz, I.; Bortolozzo, F. P.; Guidoni, A. L. Influência da temperatura corporal sobre a eficiência reprodutiva de fêmeas suínas. In: Congresso Brasileiro de Veterinários Especialistas em Suínos, 1995. Blumenau. Anais... Blumenau: ABRAVES, 1995. p.129.

Brown-Brandl, T. M.; Eigengerg, R. A.; Nienaber, J. A.; Kachman, S. D. Thermoregulatory profile of a newer genetic line of pigs. Livestock Production Science, v.71, p.253-260, 2001.

Buffington, D. E.; Colazzo-Arocho, A.; Caton, G. H. Black globe humidity comfort index (BGHI) as comfort equation for dairy cows. Transaction of the ASAE, v.24, n.4, p.711-714, 1981. 
Chang, C. W.; Chung, H.; Huang, C. F.; Su, H. J. J. Exposure assessment to airbone endotoxin, dust, ammonia, hydrogen sulfide and carbon dioxide in open style swine houses. Annals of Occupational Hygiene, v.45, n.6, p.457-465, 2001.

CIGR - Commission Internationale Du Génie Rural. Aerial environment in animal housing: Concentration in and emission from farm buildings. UCD, 1994. 116p.

Donham, K. A historical overview of research on the hazards of dust in livestock buildings. In: International Symposium on Dust Control in Animal Production Facilities, 30., 1999. Aahus. Proceedings... Horsens: Danish Institute of Agricultural Sciences, 1999. p.13-21.

Flores, B.; Cantley, T. C.; Martin, M. J.; Day, B. N. Effect of elevated ambient temperatures on puberty in gilts. Journal of Animal Science, v.67, p.779-784, 1989.

Gustafsson, M.; Jensen, P; De Jonge, F. H.; Schuurman, T. Domestication effects on foraging strategies in pigs (Sus scrofa). Applied Animal Behaviour Science, v.62, n.1, p.305-317, 1999.

Larry, D. J.; Steve, P.; William, G. B. Troubleshooting swine ventilation systems: pork industry handbook. Purdue: University Cooperative Extension Service, 1994. 6p.

Lucas, E. M.; Cruz, V. F. Efeito do clima do Alentejo no microclima das instalações para suínos. Revista Portuguesa de Zootecnia, v.4, n.1, p.37-52, 1997.

Mount, N. C.; Seabrook, M. F. A study of aggression when group housed sows are mixed. Applied Animal Behaviour Science, v.36, n.1, p.377-383, 1993.

Moura, D. J.; Nääs, I. A.; Silva, I. J. O.; Sevegnani, K. B.; Corria, M. E. The use entalpy as a thermal comfort index. In: Livestock Environment, 5, St. Joseph, 1997. Proceedings... St. Joseph: ASAE, 1997. v.1, p.242-248.

Nienaber, J. A.; Hahn, L. G.; Yen, J. T. Thermal environment effects on growing-finishing swine, Part I-Growth, feed intake and heat production. Transaction of the ASAE, v.30, n.6, p.1772-1775, 1987.

NRC - National Research Council. Nutrient requeriments of swine. 10.ed. Washington: National Academy Press, 1998. 189p.

Noblet, J.; Dourmad, J. Y.; Dividich, J.; Dubois, S. Effect of ambient temperature and addition of straw or alfafa in the diet on energy metabolism in pregnant sows. Livestock Production Science. v.21, p.309-324, 1989.
Peltoniemi, O. A. T.; Love, R. J.; Heinomen, M.; Tuovinem, V.; Saloniemi, H. Seasonal and management effects on fertility of the sow: a descriptive study. Animal Reproduction Science, v.55, p.47-61, 1999.

Perdomo, C. C.; Lima, G. J. M. M.; Nones, K. Produção de suínos e meio ambiente. In: Seminário Nacional de Desenvolvimento da Suinocultura, 9, 2001. Gramado. Anais... Gramado: CNPSA, 2001. p.11-17.

Pereira, A. R.; Angelocci, L. R.; Sentelhas, P.C. Agrometeorologia: Fundamentos e aplicações práticas. Guaíba: Agropecuária, 2002. 478p.

Perez y Perez, P.; Gutierez, J. F. P. Summer infertility of swine stock in Spain. Luxemburg: Commission of the European Communities, 1987. p.25-28.

Saliba, T. M.; Corrêa, M. A. C. Manual prático de avaliação e controle de gases e vapores. São Paulo: LTR, 2000. 132p.

Sampaio, C. A. P. Caracterização dos sistemas térmicos e acústicos em sistemas de produção de suínos nas fases de creche e terminação. Campinas: FEAGRI/UNICAMP, 2004. 121p. Tese Doutorado

Sampaio, C. A. P.; Nääs, I. A.; Nader, A. Gases e ruídos em edificações para suínos - aplicação das normas NR-15, CIGR e ACGIH. Engenharia Agrícola, v.25, n.1, p.10-18, 2005.

Sampaio, C. A. P.; Nääs, I. A.; Salgado, D. D. Amônia, gás sulfídrico, metano e monóxido de carbono na produção de suínos. Revista de Ciências Agroveterinárias, v.5, n.2, p.156-164, 2006.

SAS - Institute, Statistical analysis system: realease 6.08, (software). Cary, 1992. 620p.

Silva, I. J. O. Qualidade do ambiente e instalações na produção industrial de suínos. In: Simpósio Internacional de Suinocultura, 1999. São Paulo. Anais... São Paulo: Gessuli, 1999. p.108-325.

Vieira, H. P.; Vieira, R. P. Definition of the summer infertility problem in the pig. Luxemburg: Commission of the European Communities, 1987. 35p.

Wentz, I.; Bortolozzo, F. P.; Barcellos, D. E. S. N.; Jacobi, H. Ocorrência de síndrome de aborto em suínos no Rio Grande do Sul. In: Congresso Brasileiro de Veterinários Especialistas em Suínos, 1997. Foz do Iguaçu. Anais... Foz do Iguaçu: ABRAVES, 1997. p.301-302.

Yan, P. S.; Yamamoto, S. Relationship between thermoregulatory responses and heat loss in piglets. Journal of Animal Science, v.71, n.10, p.5005-509, 2000. 